\title{
Nature of the Nets Produced by \\ Protoplasts of Schizosaccharomyces pombe During the First Stage of Wall Regeneration in Liquid Media
}

\author{
By D. R. KREGER \\ Department of Plant Physiology, University of Groningen, The Netherlands \\ AND MARIE KOPECKÁ \\ Department of General Biology, Faculty of Medicine, J. E. Purkyně \\ University, Brno, Czechoslovakia
}

(Received 10 April 1978)

\begin{abstract}
The microfibrillar nets formed during the first stage of wall regeneration by protoplasts of Schizosaccharomyces pombe in a liquid medium contain, in contrast to normal walls, $(1 \rightarrow 3)-\beta$-linked glucan of high crystallinity, like the nets produced by protoplasts of Saccharomyces cerevisiae under the same conditions. During wall regeneration by protoplasts of Schizosaccharomyces, $\beta$-glucan synthesis precedes the formation of $(1 \rightarrow 3)$ - $\alpha$-glucan.
\end{abstract}

\section{INTRODUCTION}

The microfibrillar nets produced by protoplasts of Saccharomyces cerevisiae in liquid media are structurally and chemically different from those in normal walls (Kopecká et al., 1967). The latter are fine networks (Houwink \& Kreger, 1953; Kreger \& Kopecká, 1973, $1976 a$; Kopecká et al., 1974a) and consist mainly of $(1 \rightarrow 3)-\beta$-linked, $(1 \rightarrow 6)-\beta$-branched glucan (Manners et al., 1973). The former have much wider meshes and microfibrils with characteristic straight parts and fasciations. They contain about $40 \%$ (dry wt) unbranched $(1 \rightarrow 3)$ - $\beta$-linked D-glucan and $10 \%$ chitin, both conspicuously crystalline as is apparent from their X-ray patterns (Kreger \& Kopecká, 1973, 1976a). The crystallinity and high degree of polymerization of the unbranched glucan may explain the ultrastructural features of the nets (Kreger \& Kopecká, 1976b), while the differences between the protoplast nets and the glucan nets in normal walls have been attributed to selective removal or inhibition of $(1 \rightarrow 6)$ - $\beta$-branching enzyme by the liquid medium (Kreger \& Kopecká, 1973, 1976a).

The fission yeasts of the genus Schizosaccharomyces have cell walls containing a branched glucan with $(1 \rightarrow 3)$ - $\beta$-linked chains (Kreger, 1954, 1967; Bush et al., 1974; Manners \& Meyer, 1977), like those of Sacch. cerevisiae. The walls of Schizosaccharomyces differ from the latter in that they also contain $(1 \rightarrow 3)-\alpha$-glucan (Bacon et al., 1968). This glucan is easily identified by its X-ray pattern, even in untreated walls, and in Schiz. octosporus it constitutes over $40 \%$ of the wall dry weight (Kreger, 1954, 1967). In Schiz. pombe the percentage is lower: $28 \%$ (Bush et al., 1974) or 18\% (Manners \& Meyer, 1977).

Protoplasts of Schiz. pombe, cultivated in liquid medium, form a network of microfibrils which, in contrast to that of the protoplasts of Sacch. cerevisiae, increases in density. A new wall is formed underneath, and subsequently cell division takes place (Nečas et al., 1968 a; Havelková, 1972). The network formed within the first $2 \mathrm{~h}$ cultivation (Nečas et al., 1968 a, Fig. 10; this paper, Fig. 2) strongly resembles, in its structural features, the nets formed by protoplasts of Sacch. cerevisiae described above, suggesting that they have the same constitution. In this paper, we present evidence from X-ray diffraction and ancillary electron microscopy which supports this suggestion. 


\section{METHODS}

Schizosaccharomyces pombe (strain 44-1-3, Czechoslovak Collection of Microorganisms, Institute of Chemistry, Slovak Academy of Sciences, Bratislava) was cultivated, protoplasts were obtained, cultivated and lysed, and the nets were cleaned, according to the methods described for Sacch. cerevisiae (Kreger \& Kopecká, 1976 a). Protoplasts were cultivated for $4 \mathrm{~h}$. Walls of Schizosaccharomyces species are incompletely degraded by snail enzyme and frequently adhere as empty envelopes to the released protoplasts. Apart from the place of adherence, the surface of such protoplasts is clean (Nečas et al., 1968a). Two samples of nets were prepared: (a) a sample in which about $35 \%$ of the nets adhered to old walls; (b) a sample of which the proportion of nets that adhered to old walls had been reduced to about $10 \%$ by careful shaking and centrifugation. Methods for complete digestion of old walls (Kopecká et al., 1974b; Kopecká, 1975) were considered to be unnecessary for our purpose. Normal walls of Schiz. pombe and Schiz. octosporus were from type strains of the yeast culture collection at Delft of the Centraal Bureau voor Schimmelcultures, Baarn, and were prepared from suspensions of cells broken by shaking with ballotini glass beads in a Mickle homogenizer. Electron micrographs, X-ray diagrams and densitometer curves were obtained as indicated by Kreger \& Kopecká (1976a).

\section{RESULTS AND DISCUSSION}

The densitometer curves of the X-ray patterns from normal walls of Schiz. octosporus and Schiz. pombe, the net samples (a) and (b) from Schiz. pombe protoplasts and a net sample from Sacch. cerevisiae protoplasts are shown in Fig. 1 as curves A, B, C, D and E, respectively. Curve E in Fig. 1 is the same as Fig. 11 (b) B of Kreger \& Kopecká (1976a). These nets from Sacch. cerevisiae had been extracted with cold $30 \%(\mathrm{w} / \mathrm{v}) \mathrm{HCl}$ to remove chitin, which is not produced by Schizosaccharomyces (Roelofsen \& Hoette, 1951; Kreger, 1954).

The curves from X-ray patterns of native walls (Fig. 1, A and B) show only one peak attributable to $\beta$-glucan, which is broad and low, indicating a low crystalline order of this chain type. The $\alpha$-glucan peaks are higher in the curve from Schiz. octosporus walls than in the one from walls of Schiz. pombe, thus confirming the data (see Introduction) on the difference in $\alpha$-glucan content between these walls. The peaks represent lattice spacings of 0.917 , 0.497 and $0.423 \mathrm{~nm}$, respectively. The $\beta$-glucan spacings represented by the peaks in curve E were reported by Kreger \& Kopecká (1976a).

The samples of protoplast nets of Schiz. pombe were clearly different from each other: sample (a), with the higher content of old walls, produced considerably higher intensity peaks attributable to $\alpha$-glucan (Fig. 1, curve C) than did sample (b) (Fig. 1, curve D), while in the latter the $\beta$-glucan peaks were more pronounced. Both samples differed markedly from the native walls by the high crystallinity of the $\beta$-glucan; this is evident from the sharp inner peak $(\beta 1)$ and the appearance, in particular in curve $\mathrm{D}$, of nearly all $\beta$-glucan reflections observed in the diagram from the nets of Sacch. cerevisiae protoplasts (Fig. 1, curve E).

Comparison of curves C and B in Fig. 1 shows that the specimen of protoplast nets with many old walls gave much more pronounced $\alpha$-glucan peaks than did the native walls of Schiz. pombe. This may be explained by selective digestion of the non- $\alpha$-glucan components of the old walls during the incubation for protoplast production.

The X-ray patterns of the samples of young protoplast nets of Schiz. pombe showed that they had a high content of $(1 \rightarrow 3)-\beta$-glucan, which was well crystallized, as it is in the nets of Sacch. cerevisiae. This glucan must have been formed de novo by the protoplasts since (i) the normal walls only produced a diffuse $\beta$-glucan ring and (ii) the sample with the smaller contamination by old walls gave the better resolution of $\beta$-glucan peaks. We may conclude that during the first stage of wall regeneration Schiz. pombe protoplasts produce only or mainly $(1 \rightarrow 3)-\beta$-glucan chains, perhaps with a fraction branched in C-6, as do Sacch. cerevisiae protoplasts (Kreger \& Kopecká, 1976a). Hence, the structural similarity of the microfibrillar pattern of the young nets of Schiz. pombe protoplasts (Fig. 2) to that of the protoplast nets of Sacch. cerevisiae may be attributed to the concomitant correspondence 


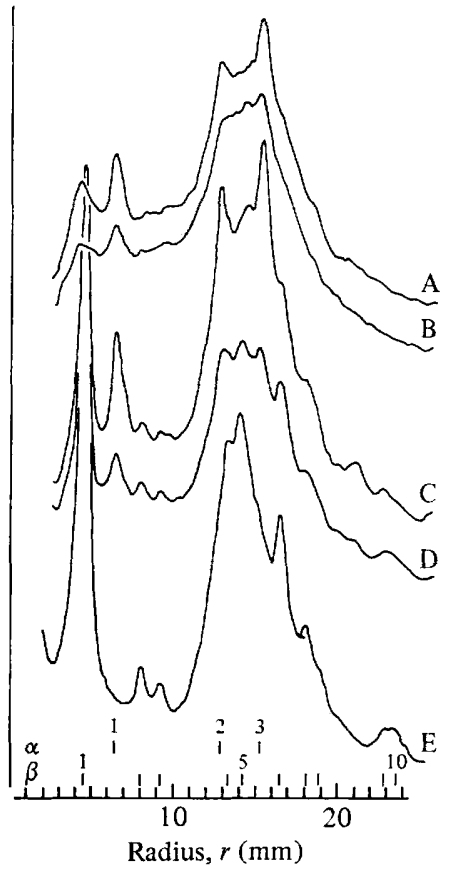

Fig. 1. Radial density distribution curves of $X$-ray patterns taken at $40 \mathrm{~mm}$ from the specimen: $\alpha 1$ to $3, \alpha$-glucan peaks; $\beta 1$ to $10, \beta$-glucan peaks. A, Normal walls of Schiz. octosporus; $\mathrm{B}$, normal walls of Schiz. pombe; C, net sample (a), about $35 \%$ of nets adhering to old walls; $\mathrm{D}$, net sample (b), about $10 \%$ of nets adhering to old walls; E, nets from protoplasts of Sacch. cerevisiae extracted with cold $30 \%$ (w/v) $\mathrm{HCl}$.

in constitution. The effect of the liquid medium on synthesis and ultrastructure of the $\beta$-glucan appeared, therefore, to be the same as in Sacch. cerevisiae (Kreger \& Kopecká, $1976 a, b)$.

The formation of nets by Sacch. cerevisiae protoplasts is inhibited by the action of snail enzyme added to the culture liquid (Kopecká et al., 1967; Svoboda \& Nečas, 1968). Apparently the $(1 \rightarrow 3)$ - $\beta$-glucan is digested before microfibril formation takes place. Similarly, the young nets of Schiz. pombe protoplasts discussed here were not formed if snail enzyme was added to the medium (Havelková, 1972); this supports the preceding conclusion that they consist of $(1 \rightarrow 3)$ - $\beta$-glucan. Nevertheless, with protoplasts of Schiz. pombe, in contrast to those of Sacch. cerevisiae, net formation is not completely inhibited by the action of snail enzyme (Havelková, 1972). After $24 \mathrm{~h}$ cultivation an incomplete wall was formed with a structure (Havelková, 1972, Fig. 7) which, though not well resolved, was different from that of the $(1 \rightarrow 3)-\beta$-glucan nets shown in Fig. 2 . This material was obviously not attacked by snail enzyme, as is also the case with $(1 \rightarrow 3)-\alpha$-glucan (de Vries \& Wessels, 1973). We repeated this experiment with $14 \mathrm{~h}$ cultivation. Examination of the nets obtained at higher magnification (Fig. 3) revealed that they only contained rather short microfibrils with a nodose, rope-like appearance, characteristic of specimens rich in $(1 \rightarrow 3)-\alpha$-glucan (Carbonell et al., 1970; San-Blas \& Carbone11, 1974). No trace of the microfibrils like those in Fig. 2 could be detected. However, when sample (a), containing both $\alpha$ - and $\beta$-glucan (Fig. 1, curve $C$ ), was dissolved in dilute alkali and precipitated, both the nodose, short type and the long microfibrils were visible (Fig. 4). The latter are similar to those of the $(1 \rightarrow 3)-\beta$-glucan of the nets of Sacch. cerevisiae after the same treatment (Kreger \& Kopecká, 1976a, Fig. 9). These observations are evidence that the polysaccharide of the incomplete wall formed in a medium with snail enzyme is $(1 \rightarrow 3)-\alpha$-glucan. 

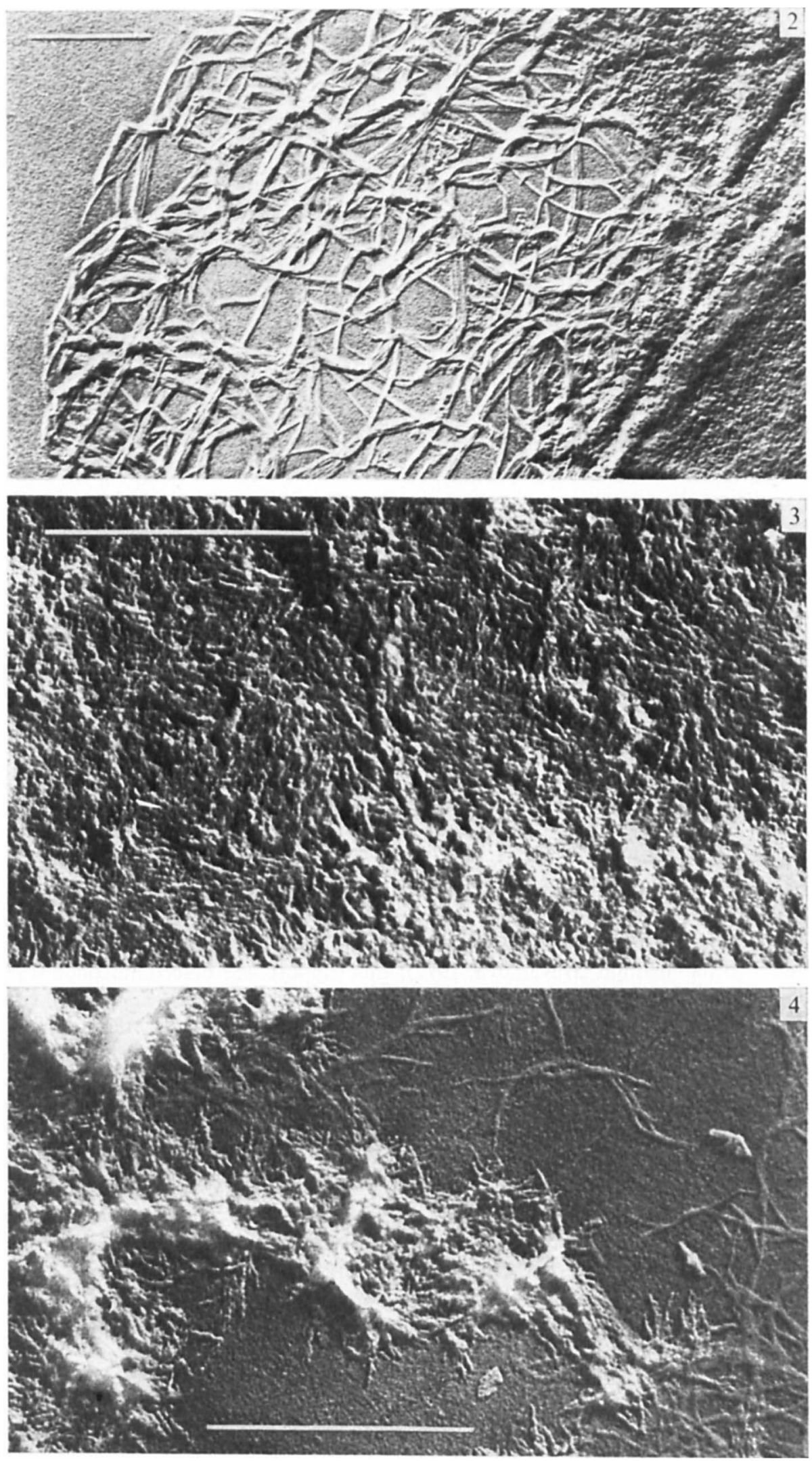

Figs. 2, 3 and 4. For legend see opposite. 
The present X-ray data combined with our electron micrographs and those published by Nečas et al. (1968a) and Havelková (1972) lead to the conclusion that in wall regeneration by Schiz. pombe protoplasts the formation of $\beta$-glucan precedes $\alpha$-glucan synthesis. This result differs from the observation made in a study of the chemistry of wall regeneration in Schizophyllum commune by de Vries \& Wessels (1975). These authors showed that synthesis of the $\beta$-glucan of these walls lagged behind for a considerable time after the formation of $\alpha$-glucan and chitin had begun. Obviously the kinetics of wall regeneration are different in these fungi. Such a difference is also indicated by the observation that cycloheximide inhibits $\beta$-glucan formation in Schizophyllum commune protoplasts (de Vries \& Wessels, 1975 ) whereas in yeast protoplasts (Sacch. cerevisiae in a solid medium) it had the effect that only the microfibrillar fraction of the wall (i.e. the $\beta$-glucan fraction) was formed and formation of the matrix (i.e. the mannan-protein fraction) was inhibited (Nečas et al., 1968b; Elorza \& Sentandreu, 1969). Since cycloheximide inhibits protein synthesis, the latter difference might be explainable, as noted by de Vries \& Wessels (1975), if peptides form part of the $\beta$-glucan complex in the walls of Schizophyllum commune.

Another example of a young microfibrillar net, reminiscent on structural grounds of those produced by Sacch. cerevisiae and Schiz. pombe protoplasts, is the net produced by protoplasts of Nadsonia elongata (Havelková, 1969, Figs 9 and 10). Since its formation was also inhibited by snail enzyme [under these conditions a different net was formed, which was soluble in cold $30 \%(\mathrm{w} / \mathrm{v}) \mathrm{HCl}$ and therefore chitinous] (Havelková, 1972, Fig. 6) and the normal walls of Nadsonia elongata contain the $\beta$-glucan found in Sacch. cerevisiae walls (Kreger, 1954), these microfibrils are most probably also of the crystalline $(1 \rightarrow 3)$ - $\beta$-glucan type. It seems, therefore, that in wall regeneration by protoplasts of yeast species whose walls contain a $(1 \rightarrow 3)$ - $\beta$-linked glucan branched in $\mathrm{C}-6$, a liquid culture medium generally effects a deficiency in $(1 \rightarrow 6)-\beta$-branching enzyme, which gives rise to the synthesis of long chains with $(1 \rightarrow 3)-\beta$-links only and concomitant structural features of the microfibrils and nets due to a preponderance of this chain type.

\section{REFERENCES}

Bacon, J. S. D., Jones, D., Farmer, V. C. \& WEBLEY, D. M. (1968). The occurrence of $\alpha-(1 \rightarrow 3)$ glucan in Cryptococcus, Schizosaccharomyces and Polyporus species, and its hydrolysis by a Streptomyces culture filtrate lysing cell walls of Cryptococcus. Biochimica et biophysica acta 158, 313-315.

Bush, D. A., Horisberger, M, Horman, I. \& Wursch, P. (1974). The wall structure of Schizosaccharomyces pombe. Journal of General Microbiology 81, 199-206.

Carbonell, L. M., Kanetsuna, F. \& Gil, F. (1970). Chemical morphology of glucan and chitin in the cell wall of the yeast phase of Paracoccidioides brasiliensis. Journal of Bacteriology 101, 636-642.

Elorza, M. V. \& Sentandreu, R. (1969). Effect of cycloheximide on yeast cell wall synthesis. Biochemical and Biophysical Research Communications 36, 741-747.

HAVELKovÁ, M. (1969). Mechanism of regeneration of yeast protoplasts. VII. Electron microscopy of growing and regenerating protoplasts of Nadsonia elongata. Folia biologica (Praha) 15, 462-469.

HAVELKová, M. (1972). Experimental inhibition of cell wall formation and of reversion in Nadsonia elongata and Schizosaccharomyces pombe protoplasts. Protoplasma 75, 405-419.

Houwink, A. L. \& KREGER, D. R. (1953). Observations on the cell walls of yeasts. An electron microscope and X-ray diffraction study. Antonie van Leeuwenhoek 19, 1-24.

KOPECKÁ, M. (1975). The isolation of protoplasts of the fission yeast Schizosaccharomyces by Tricho-

All bar markers represent $1 \mu \mathrm{m}$.

Fig. 2. Net formed after $2 \mathrm{~h}$ on protoplast of Schiz. pombe, with adhering old wall on right side. Long microfibrils of $(1 \rightarrow 3)$ - $\beta$-glucan.

Fig. 3. Net formed after $14 \mathrm{~h}$ on protoplast of Schiz. pombe in culture medium with snail enzyme. Short, nodose type of microfibrils of $(1 \rightarrow 3)$ - $\alpha$-glucan only; old wall, bottom right.

Fig. 4. Precipitate from neutralized alkali extract from nets of sample (a), with short, nodose and long microfibrils. 
derma viride and snail enzymes. Folia microbiologica (Praha) 20, 273-276.

KopeCKÁ, M., CTtRVRTNíČEK, O. \& NeČAS, O. (1967). Formation and properties of fibrillar network formed in yeast protoplasts as the first step of biosynthesis of cell wall. In Symposium über Hefe-Protoplasten, pp. 73-76. Edited by R. Müller. Berlin: Akademie-Verlag.

Kopecká, M., Phaff, H. J. \& Fleet, G. H. (1974a). Demonstration of a fibrillar component in the cell wall of the yeast Saccharomyces cerevisiae and its chemical nature. Journal of Cell Biology 67 , 66-76.

Kopecká, M., PhafF, H. J., \& Fleet, G. H. (1974b). The ultrastructure of the yeast cell wall after enzymic degradation by purified enzymes. In Proceedings of the Fourth International Symposium on Yeasts, Part I, D8. Edited by $\mathrm{H}$. Klaushofer \& U. B. Sleytr. Vienna: Hochschülerschaft an der Hochschule für Bodenkultur.

KREGER, D. R. (1954). Observations on cell walls of yeasts and some other fungi by X-ray diffraction and solubility tests. Biochimica et biophysica acta 13, 1-9.

KREGER, D. R. (1967). Röntgenographical aspects of yeast cell walls with particular reference to the glucan components (baker's yeast, Saccharomycopsis guttulata, Schizosaccharomyces octosporus and Candida albicans). In Symposium über Hefe-Protoplasten, pp. 81-88. Edited by R. Müller. Eerlin: Akademie-Verlag.

KREGER, D. R. \& KopeCKÁ M. (1973). On the nature of the fibrillar nets formed by protoplasts of Saccharomyces cerevisiae in liquid media. In Yeast, Mould and Plant Protoplasts, Proceedings of the Third International Symposium on Yeast Protoplasts, Salamanca, pp. 117-130. Edited by J. R. Villaneuva, I. Garciá-Acha, S. Gascón \& F. Uruburu. London: Academic Press.

KREGER, D. R. \& KopeckÁ, M. (1976a). On the nature and formation of the fibrillar nets produced by protoplasts of Saccharomyces cerevisiae in liquid media: an electronmicroscopic, X-ray diffraction and chemical study. Journal of General Microbiology 92, 207-220.
KREGER, D. R. \& KOPECKÁ, M. (1976b). Assembly of wall polymers during the regeneration of yeast protoplasts. In Microbial and Plant Protoplasts, pp. 237-252. Edited by J. F. Peberdy, A. H. Rose, H. J. Rogers \& E. C. Cocking. London: Academic Press.

Manners, D. J. \& Meyer, M. T. (1977). The molecular structures of some glucans from the cell walls of Schizosaccharomyces pombe. Carbohydrate Research 57, 189-203.

Manners, D. J., Masson, A. J. \& Patterson, J. C. (1973). The structure of a $\beta-(1 \rightarrow 3)$-D-glucan from yeast cell walls. Biochemical Journal 135, 19-30.

NeČAs, O., Svoboda, A. \& Havelková, M. (1968a). Mechanism of regeneration of yeast protoplasts. V. Formation of the cell wall in Schizosaccharomyces pombe. Folia biologica (Praha) 14, 80-85.

NeČAs, O., Svoboda, A. \& KopeckÁ, M. (1968 b). The effect of cycloheximide (actidione) on the cell wall synthesis in yeast protoplasts. Experimental Cell Research 53, 291-293.

Roelofsen, P. A. \& Hoette, I. (1951). Chitin in the cell wall of yeasts. Antorie van Leeuwenkoek 17, 27-34.

San-Blas, G. \& Carbonell, L. M. (1974). Chemical and ultrastructural studies on the cell walls of the yeastlike and mycelial forms of Histoplasma farciminosum. Journal of Bacteriology 119, 602611.

Svoboda, A. \& NeČAs, O. (1968). Mechanism of regeneration of yeast protoplasts. VI. An experimental blocking of regeneration of protoplasts. Folia biologica (Praha) 14, 390-397.

VRIES, O. M. H. dE \& WeSSELS, J. G. H. (1973). Release of protoplasts from Schizophyllum commune by combined action of purified $\alpha-(1 \rightarrow 3)$ glucanase and chitinase derived from Trichoderma viride. Journal of General Microbiology 76, 319330.

VRIES, O. M. H. de \& Wessels, J. G. H. (1975). Chemical analysis of cell wall regeneration and reversion of protoplasts from Schizophyllum commune. Archives of Microbiology 102, 209-218. 